\title{
Hierarchical Control for the Start-up procedure of Solar Thermal Fields with Direct Storage
}

\author{
Juan D. Gil ${ }^{\mathrm{a}}$, Lidia Roca ${ }^{\mathrm{a}, \mathrm{b}}$, Guillermo Zaragoza ${ }^{\mathrm{b}}$, Julio E. Normey-Rico ${ }^{\mathrm{c}}$, \\ Manuel Berenguel ${ }^{\mathrm{a}, *}$ \\ ${ }^{a}$ Centro Mixto CIESOL, ceiA3, Universidad de Almería. Ctra. Sacramento s/n, Almería \\ 04120, Spain; \{juandiego.gil,beren\}@ual.es \\ ${ }^{b}$ CIEMAT-Plataforma Solar de Almería, Ctra. de Senés s/n, Tabernas 04200, Almería, \\ Spain; \{lidia.roca,guillermo.zaragoza\}@psa.es \\ ${ }^{c}$ Federal University of Santa Catarina, Department of Automation and Systems, \\ Florianpolis, Brazil; julio.normey@ufsc.br
}

\begin{abstract}
Thermal energy storage tanks are habitually combined with solar thermal fields to improve the dispatchability of these facilities. From the dynamical point of view, the start-up phase is relevant since if the storage device is unloaded in terms of energy or widely stratified, the transitory regime can take long time until reaching the operating point. In this paper, an optimal real-time procedure based on a hierarchical controller for improving the start-up phase is proposed. The hierarchical controller is composed of two layers based on a Model Predictive Control (MPC) technique and Proportional Integer Derivative (PID) controllers. Real experimental tests were performed in a pilot facility located at Plataforma Solar de Almería (Almería, Spain). In addition, a comparison in simulation with the typical manual procedure and with two techniques proposed previously in the literature for the same plant is provided. The results demonstrate the benefits obtained by using the proposed method; since it reduces the start-up phase in 34 [min] in comparison with the manual operation, and in 26 and 6 [min] with respect to the two previous techniques.

Keywords: Process Control, Solar Energy, Hierarchical Control, Model

Predictive Control.
\end{abstract}

\footnotetext{
${ }^{*}$ Corresponding author.

Email address: beren@ual.es (Manuel Berenguel)
}

Preprint submitted to Control Engineering Practice

July 18, 2019 


\section{Introduction}

In recent decades, the depletion of non-renewable energy resources such as fossil fuels, as well as the growing concern for atmospheric pollution, have led to an intensive search for alternative energy solutions, among which, solar thermal energy stands out. This technology plays a major role in any scenario of sustainable and efficient development with adequate conditions of solar irradiance, both to generate electricity and to feed thermal powered processes. Although the installation of solar thermal plants is spread throughout the world, there is still room for investigating and improving aspects that range from the design to the operation of these kind of plants (Kumar et al. 2018).

From the design point of view, as solar energy is an intermittent source, the integration of thermal storage systems in these kind of facilities has become a key factor to increase the performance of the technology (Rovira et al., 2011 Pelay et al., 2017; Gibb et al., 2018). Considering the solar field, the storage device, and the power block or the thermal load (depending of the kind of process powered), several layout configurations can be found in the literature attending to the number of storage tanks used in the facility, and the way in which they are connected to the system (Biencinto et al., 2014). These layouts mainly are (see Fig. 1 (a)-(d)): i) two-tank with indirect storage, as the ANDASOL 3 plant which is described in Dinter \& Gonzalez (2014), ii) single-tank with indirect storage, as the facility analyzed in Kolb (2011) and most of the low concentration solar plants (Abid et al., 2018), iii) two-tank with direct storage, as the GEMASOLAR plant (Casella et al. 2014), and iv) single tank with direct storage as the ACUREX plant (Camacho \& Gallego, 2013). It should be remarked that this last layout is also used in most of low concentration applications (Artur et al., 2018). These configurations are the most used in the literature but not the only ones, since this is an open research field in which there are many authors proposing new designs (Sebastián et al., 2018) and connection modes between the different devices (Rovira et al., 2011; Li et al., 2019). 
(a)

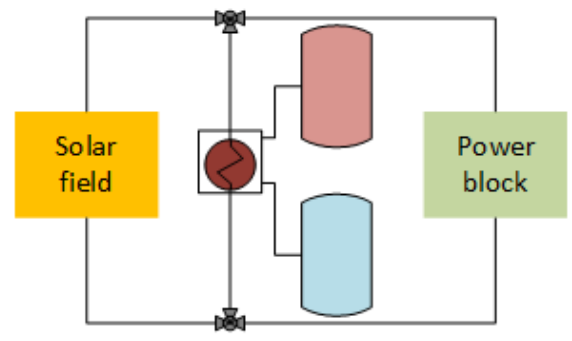

(c)

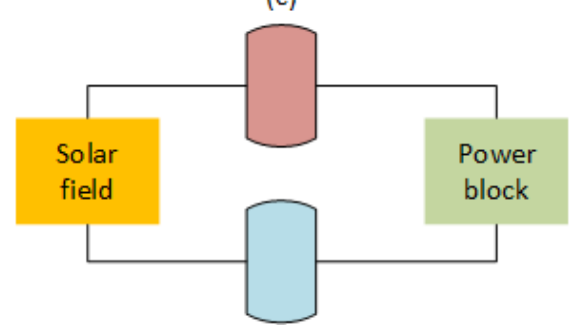

(b)

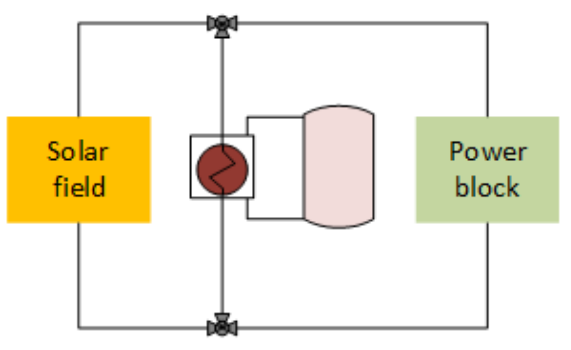

(d)

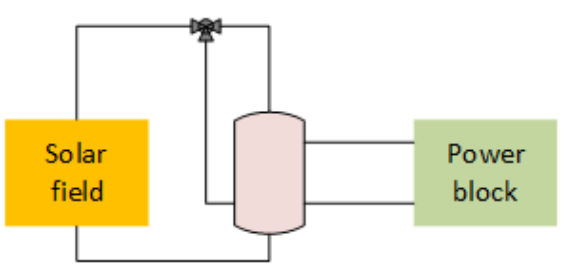

Figure 1: Simplified schematic diagrams of the main thermal solar fields described in the literature. (a) Two-tank with indirect storage, adapted from Dinter \& Gonzalez (2014), (b) single tank with indirect storage, adapted from Kolb 2011), (c) two-tank with direct storage, adapted from Casella et al. (2014), and (d) single tank with direct storage, adapted from Camacho \& Gallego (2013).

Even though the use of storage devices enables longer or continuous operations of the powered systems, and helps to balance transients caused by irradiance disturbances, only around $50 \%$ of the concentrated solar power facilities currently in operation include these kind of devices (Pelay et al., 2017). However, the continuous progress in thermal energy storage technology Kuravi et al., 2013), and the necessity of using it to make solar thermal energy competitive, have caused around $70 \%$ of the facilities in construction to include storage systems (Pelay et al. 2017). In this way, the development of accurate operation strategies aimed at maximizing the performance of these facilities is essential.

Various works have been presented in the literature proposing operating methodologies for the plant configurations shown in Fig. 1. For the case of two- 
tank with indirect storage, in Relloso \& Delgado (2009) the operating modes for the day and night times of ANDASOL 1 plant were described. In the same way, the operation of the ANDASOL 3 plant was documented in Dinter \& Gonzalez (2014), presenting several operating modes to maximize the economic benefits. In Biencinto et al. (2014), different modes for charging and discharging the tanks were presented and analyzed using a simulation environment, and in Guédez et al. (2015), an operating mode for minimizing the number of turbine starts was proposed. The operating strategy can be a solution of an optimization problem such as that presented in Usaola (2012); with the aim of maximizing the revenues and taking into consideration the daily electricity prices. Besides, an optimal-control framework was proposed in Rubio et al. (2018) to maximize the thermal power supplied by the solar field. Regarding the single-tank with indirect storage configuration, an operating mode aimed at minimizing the thermocline degradation was presented in Biencinto et al. (2014), and compared with the operation of a two-tank with indirect storage based plant. Similarly, in Kolb (2011), the operating modes of these two configurations were compared. In the case of two-tanks with direct storage, in Casella et al. (2014), an optimal control procedure was presented for the operation of these kind of plants according to the variable electricity tariffs. A more extended control algorithm was proposed in Casati et al. (2015) with the same aim. Moreover, optimal start-up policies were presented in Lopez-Alvarez et al. (2018) which were obtained by means of a dynamical-optimization problem. Finally, in the case of single-tank with direct connection, a hierarchical control architecture was proposed in Berenguel et al. (2005); with the objective of maximizing the electricity production by optimizing in real-time the operation of the facility. A similar approach was proposed in Camacho \& Gallego (2013), but in this case aimed at reducing thermal losses in the solar field.

Although all these works present optimal operating methodologies, the startup procedure has hardly been addressed. A suitable start-up policy is essential not only for the first operation days, but also for the daily operation, especially in configurations with direct storage. In these kind of plants, the start-up proce- 
dure is usually performed using heuristic-rules, which are formulated according to the storage device states Cirre (2007). However, these rules can be inefficient since they do not explicitly take into consideration the operating constraints and the process disturbances. In facilities with two tanks with direct storage (see Fig 1 1 (c)), the start-up problem has been already addressed by Lopez-Alvarez et al. (2018). In that work, an off-line dynamical-optimization problem was proposed for computing the optimal flow rate according to the states of the hot and cold tanks and irradiance conditions, trying to achieve full operation from shutdown as fast as possible. Nevertheless, in this off-line dynamical-optimization method, it was assumed that there were no process disturbances or model uncertainties, which is an ideal situation that does not happen in real operations, particularly if the disturbances are mainly caused by irradiance.

In this paper, a real-time start-up procedure for a solar field plant with singletank with direct storage configuration is proposed. The procedure is based on a hierarchical controller composed by two layers. The upper one includes a Model Predictive Control (MPC) strategy that is responsible for computing the setpoints for the lower layer with the objective of maximizing the temperature in the storage device as fast as possible. Note that this layer takes into account the operating conditions at each sampling time unlike the approach proposed in Lopez-Alvarez et al. (2018). The lower layer includes Proportional Integral Derivative (PID) controllers which are in charge of tracking the setpoints provided by the upper layer by acting on the two actuators available in these kind of solar fields: flow rate and valve aperture (see Fig. 1. (d)). The proposed method has been tested in a real facility located at Plataforma Solar de Almería (PSA). In addition, a comparison with two start-up methods previously proposed for the same facility and with a manual operation is provided, showing that the start-up stage time can be reduced up to $10.5 \%$ with the proposed methodology, compared to the manual operation mode. 


\section{Plant description}

The facility used as reference in this paper (see Fig. 2) is located in PSA (www.psa.es), and it is a test-bed for evaluating solar membrane distillation modules (Zaragoza et al., 2014). The layout of the system is shown in Fig. 3. and it includes a solar thermal field, a storage device and a membrane distillation module (thermal load).

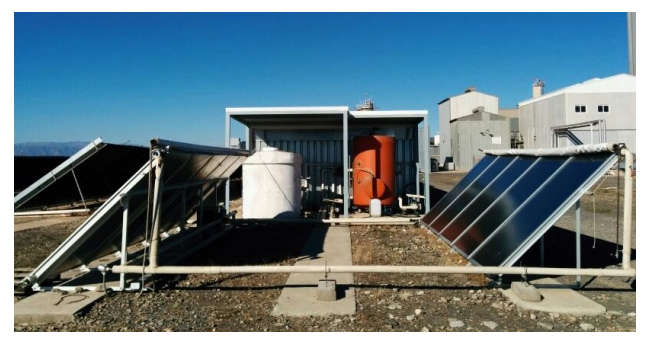

Figure 2: Real facility at PSA.

The solar field of the facility is based on stationary flat-plate collectors Solaris CP1 Nova of $2 \mathrm{~m}^{2}$, commercialized by Solaris (Spain). The collectors are disposed in two rows including five collectors each one. The nominal thermal power at about $90{ }^{\circ} \mathrm{C}$ is $7 \mathrm{~kW}$, using water with antifreeze as heat transfer medium. In addition, the solar field is equipped with an expansion vessel and a cut valve (valve 2 in Fig. 3), which are used to absorb circuit pressure increases and protect the flat-plate collectors from evaporations. In particular, the valve is closed when the facility is not in operation, so if the temperature of the solar fluid increases and vapour is produced inside the absorber pipes, it flows to the expansion vessel. When the solar pump is turned on, the valve is opened and the water inside the expansion vessel is pushed again towards the collectors.

The solar field is directly linked with a thermal storage tank with a volume of $1.5 \mathrm{~m}^{3}$. This device is used to balance transients and irradiance disturbances, as well as a buffer system to store thermal energy. The other side of the tank is connected with the thermal load which in this case is a membrane distillation unit, as was previously mentioned. Note that this connection is made through 
a heat exchanger, which is included in the membrane distillation unit. This technology, as most solar powered processes, requires a minimum operating temperature which in this case is $60^{\circ} \mathrm{C}$ (Gil et al., 2018b). This fact implies that the storage tank must be at a certain operating point in terms of temperature before feeding the membrane distillation unit.

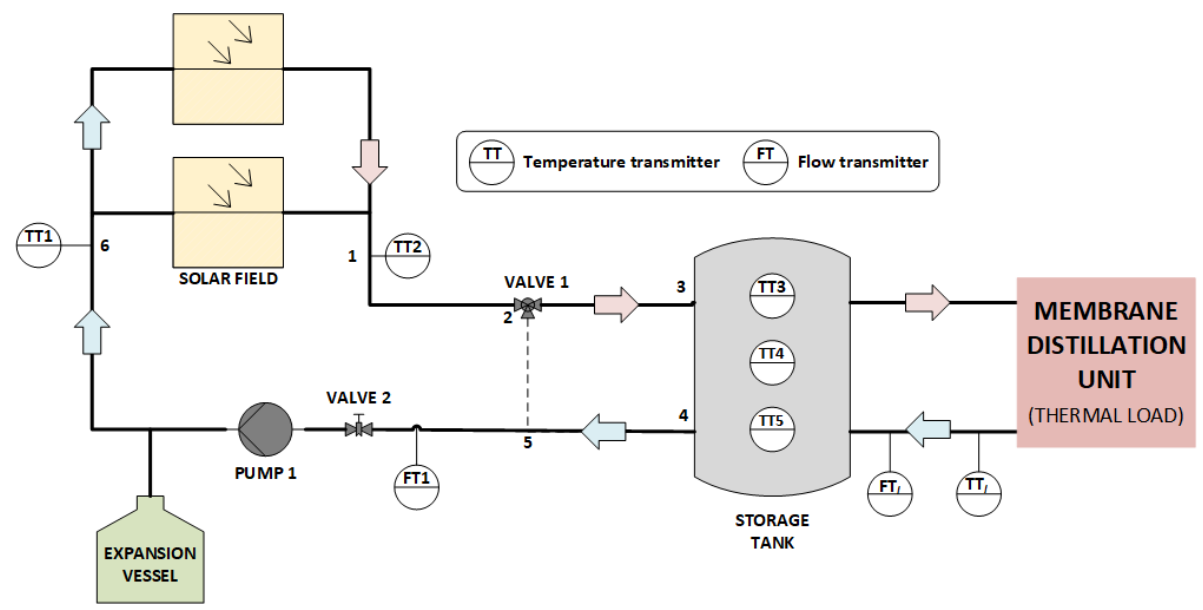

Figure 3: Schematic diagram of the facility.

A Supervisory Control And Data Acquisition (SCADA) system is in charge of monitoring and controlling the installation with a 1 second sampling time. This system is coupled to the plant by means of an advanced data acquisition system manufactured by National Instruments. The measured and controlled variables of interest for this work are summarized in Table 1.

\section{System modeling}

The facility was completely modeled in order to design the control system and perform simulation tests. Notice that the calibration and validation procedures of the models were already presented in Gil et al. (2018c).

Firstly, the outlet solar field temperature was modeled using a lumpedparameter model as the one described in Roca et al. (2008). In this model, the outlet solar field temperature (TT2) is calculated based on the main vari- 


\begin{tabular}{lll}
\hline Variable & Description & Unit \\
\hline $\mathrm{FT}_{l}$ & Water flow rate coming from the load to the tank & {$[\mathrm{L} / \mathrm{min}]$} \\
$\mathrm{F}_{\mathrm{P} 1}$ & Pump 1 input frequency percentage & {$[\%]$} \\
$\mathrm{FT} 1$ & Solar field water flow rate & {$[\mathrm{L} / \mathrm{min}]$} \\
$\mathrm{T}_{a}$ & Ambient temperature & {$\left[{ }^{\circ} \mathrm{C}\right]$} \\
$\mathrm{TT}_{l}$ & Temperature coming from the load to the tank & {$\left[{ }^{\circ} \mathrm{C}\right]$} \\
$\mathrm{TT} 1$ & Inlet solar field temperature & {$\left[{ }^{\circ} \mathrm{C}\right]$} \\
$\mathrm{TT} 2$ & Outlet solar field temperature & {$\left[{ }^{\circ} \mathrm{C}\right]$} \\
$\mathrm{TT} 3$ & Temperature at the top of the tank & {$\left[{ }^{\circ} \mathrm{C}\right]$} \\
$\mathrm{TT} 4$ & Temperature around the middle of the tank & {$\left[{ }^{\circ} \mathrm{C}\right]$} \\
$\mathrm{TT} 5$ & Temperature at the bottom of the tank & {$\left[{ }^{\circ} \mathrm{C}\right]$} \\
$\mathrm{V} 1$ & V1 position & {$[\%]$} \\
\hline
\end{tabular}

Table 1: Variables measured at the facility.

ables that affect its performance: i) global irradiance (I), ii) inlet solar field temperature (TT1), iii) ambient temperature $\left(\mathrm{T}_{a}\right)$, and iv) solar field water flow rate (FT1). The model is formulated as follows:

$A_{c} \cdot \rho \cdot c_{p} \cdot \frac{d \mathrm{TT} 2(t)}{d t}=\beta \cdot \mathrm{I}(t)-\frac{H}{L_{e q}} \cdot\left(\overline{\mathrm{T}}(t)-\mathrm{T}_{a}(t)\right)-c_{p} \cdot \dot{m}_{e q}(t) \cdot \frac{\mathrm{TT} 2(t)-\mathrm{TT} 1(t)}{L_{e q}}$,

where:

$$
L_{e q}=L \cdot n_{c s}, \quad \dot{m}_{e q}(t)=\frac{\mathrm{FT} 1(t) \cdot \rho}{c_{f}}, \quad \overline{\mathrm{T}}(t)=\frac{\mathrm{TT} 1(t)+\mathrm{TT} 2(t)}{2} .
$$

Notice that all the variables are defined in Tables 1 and 4 and the fluid considered in the model was water without antifreeze.

Secondly, TT1 was computed according to the mix produced in the three way mixing valve (Valve 1 in Fig. 3), which was modeled by means of a static mass balance:

$$
\operatorname{TT} 1(t)=\operatorname{TT} 2(t) \cdot \frac{\mathrm{V} 1_{\mathrm{m}}(t)}{100}+\operatorname{TT} 5(t) \cdot\left(1-\frac{\mathrm{V} 1_{\mathrm{m}}(t)}{100}\right),
$$

where $\mathrm{V} 1_{\mathrm{m}}$ was calculated according to the nonlinear static characteristic curve of the valve, which relates the fraction of the mass flow with the position of the 
valve stem. For modeling this nonlinear behaviour, several experimental tests were carried out, introducing positive and negative steps in the valve aperture, observing the static values of TT1, TT2 and TT5, and calculating with Eq. (3) the value of $\mathrm{V} 1_{\mathrm{m}}$. Then, the experimental points were fitted by five order polynomials. Thereby, $\mathrm{V} 1_{\mathrm{m}}$ for positive variations of the valve aperture was calculated as:

$$
\begin{aligned}
\mathrm{V} 1_{\mathrm{m}}(t) & =1.6562 \cdot 10^{-7} \cdot \mathrm{V} 1(t)^{5}-4.1953 \cdot 10^{-5} \cdot \mathrm{V} 1(t)^{4} \\
& +0.0033 \cdot \mathrm{V} 1(t)^{3}-0.0664 \cdot \mathrm{V} 1(t)^{2}+0.3292 \cdot \mathrm{V} 1(t)
\end{aligned}
$$

whereas for the negative ones it was calculated as:

$$
\begin{aligned}
\mathrm{V} 1_{\mathrm{m}}(t) & =-3.3958 \cdot 10^{-7} \cdot \mathrm{V} 1(t)^{5}+7.2667 \cdot 10^{-5} \cdot \mathrm{V} 1(t)^{4} \\
& -0.0053 \cdot \mathrm{V} 1(t)^{3}+0.1719 \cdot \mathrm{V} 1(t)^{2}-1.8433 \cdot \mathrm{V} 1(t) .
\end{aligned}
$$

Moreover, both equations were limited between 0 and 100, which is the operating range of V1. Fig. 4 shows the adjustment between the experimental points and the polynomials.

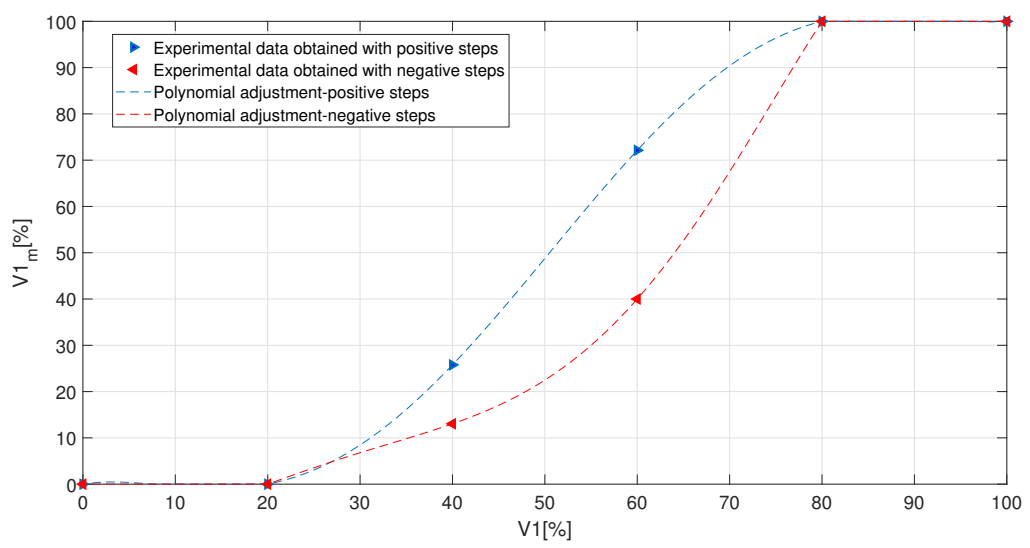

Figure 4: Valve aperture fitting.

Thirdly, the storage tank was modeled using a three-nodes stratified dynamic model, following the ideas presented in Duffie \& Beckman (2013). Thus, the 
temperature of each node was calculated by means of an energy balance as:

$$
\begin{aligned}
& \frac{d \mathrm{TT} 3(t)}{d t}=\frac{1}{\rho \cdot V_{1}} \cdot\left[\dot{m}_{s f}(t) \cdot(\mathrm{TT} 2(t)-\mathrm{TT} 3(t))\right. \\
& \left.+\dot{m}_{l}(t) \cdot(\mathrm{TT} 4(t)-\mathrm{TT} 3(t))-\frac{\alpha_{1} \cdot\left(\mathrm{TT} 3(t)-\mathrm{T}_{a}(t)\right)}{c_{p}}\right], \\
& \frac{d \mathrm{TT} 4(t)}{d t}=\frac{1}{\rho \cdot V_{2}} \cdot\left[\dot{m}_{s f}(t) \cdot(\mathrm{TT} 3(t)-\mathrm{TT} 4(t))\right. \\
& \left.+\dot{m}_{l}(t) \cdot(\operatorname{TT} 5(t)-\mathrm{TT} 4(t))-\frac{\alpha_{2} \cdot\left(\mathrm{TT} 4(t)-\mathrm{T}_{a}(t)\right)}{c_{p}}\right], \\
& \frac{d \mathrm{TT} 5(t)}{d t}=\frac{1}{\rho \cdot V_{3}} \cdot\left[\dot{m}_{s f}(t) \cdot(\mathrm{TT} 4(t)-\mathrm{TT} 5(t))\right. \\
& \left.+\dot{m}_{l}(t) \cdot\left(\mathrm{TT}_{l}(t)-\operatorname{TT} 5(t)\right)-\frac{\alpha_{3} \cdot\left(\mathrm{TT} 5(t)-\mathrm{T}_{a}(t)\right)}{c_{p}}\right] .
\end{aligned}
$$

All the variables and parameters are also defined in Tables 1 and 4 . It should be remarked that, although the stratification volumes vary with respect to the time, constant volumes according to the actual position of the temperature transmitters in the tank were identified. Besides, the parameters modeling the thermal losses were obtained by using real data and characterization techniques as presented in Gil et al. (2018b c).

Fourthly, as the solar field water flow rate was varying during the daily operation due to the control system performance, the residence time of the fluid in the pipes was not constant. Therefore, there were variable transport delays which had to be estimated and included in the model to perform accurate simulations of the system, especially to test the controller (as control loops were affected by varying delays). These transport delays were estimated as flow-dependent delays as proposed in Normey-Rico et al. (1998). Taking into account that the flow rate changes at each sampling time $t_{s}$, the transport delay, $t_{r, i-j}$, can be estimated as integer multiples, $n_{i-j}$, of the sampling time, that is $n_{i-j} \cdot t_{s} \approx t_{r, i-j}$. Thus, the value of $n_{i-j}$ was computed at each sampling time as:

$$
l_{i-j}=\int_{0}^{t_{r, i-j}} v_{i-j}(t) d t \rightarrow l_{i-j}=\frac{t_{s}}{A_{p}} \sum_{h=0}^{h=n_{i-j}-1} f_{i-j}(k-1),
$$


where $i$ and $j$ are referred to the points 1,2, ., 6 presented in Fig. 3, with $i-j \in\{1-2,2-3,2-5,4-5,5-6\}, k$ is the actual sampling time, and the rest of parameters are defined in Tables 2 and 4 . It should be noted that the temperature transmitters TT1 and TT2 are located right at the inlet and at the outlet of the solar field respectively, and therefore, the flow-dependent delays between these transmitters and the solar field were not significant.

\begin{tabular}{cc}
\hline Distance between points $\left(l_{i-j}\right)$ & Value \\
\hline$l_{1-2}$ & $15.30[\mathrm{~m}]$ \\
$l_{2-3}$ & $1.73[\mathrm{~m}]$ \\
$l_{2-5}$ & $0.77[\mathrm{~m}]$ \\
$l_{4-5}$ & $1.69[\mathrm{~m}]$ \\
$l_{5-6}$ & $12.12[\mathrm{~m}]$ \\
\hline
\end{tabular}

Table 2: Distance between points.

Finally, several transfer functions of the First Order Plus Dead Time (FOPDT) were employed to model the effect of the control variables and actuators involved in the system with respect to the controlled variables. These transfer functions were experimentally obtained, performing open-loop tests with step changes in the actuators, and using the reaction curve method to obtain the parameters of the FOPDT transfer functions as done in Gil et al. (2018c). In Table 3 the transfer functions, $G(s)=Y(s) / U(s)=K \cdot e^{-t_{d} s} /(\tau \cdot s+1)$, for the mean operating range of each of the control variables are shown, where $K$ is the static gain, $\tau$ the representative time constant, and $t_{d}$ the delay time.

\begin{tabular}{llllll}
\hline$G(s)$ & $Y(s)$ & $U(s)$ & $K$ & $\tau[s]$ & $t_{d}[s]$ \\
\hline$G_{1}(s)$ & $\mathrm{FT} 1(s)$ & $\mathrm{F}_{\mathrm{P} 1}(s)$ & $0.234[\mathrm{~L} / \mathrm{min} \cdot \%]$ & 5 & 1 \\
$G_{2}(s)$ & $\mathrm{TT} 2(s)$ & $\mathrm{FT} 1(s)$ & $-1.37\left[{ }^{\circ} \mathrm{C} \cdot \mathrm{min} / \mathrm{L}\right]$ & 66.62 & 16 \\
$G_{3}(s)$ & $\mathrm{TT} 1(s)$ & $\mathrm{V} 1(s)$ & $0.102\left[{ }^{\circ} \mathrm{C} / \%\right]$ & 43 & 79 \\
\hline
\end{tabular}

Table 3: Transfer functions experimentally obtained. 


\begin{tabular}{|c|c|c|}
\hline Parameter & Description & Unit \\
\hline$A_{c}$ & Collector cross-section area & $1.539 \cdot 10^{-4}\left[\mathrm{~m}^{2}\right]$ \\
\hline$A_{p}$ & Pipe cross-section area & $7.068 \cdot 10^{-4}\left[\mathrm{~m}^{2}\right]$ \\
\hline \multirow[t]{3}{*}{$c_{f}$} & Conversion factor to account for & $3.6 \cdot 10^{6}\left[\mathrm{~s} \cdot \mathrm{L} / \mathrm{min} \cdot \mathrm{m}^{3}\right]$ \\
\hline & connections, number of modules & \\
\hline & and $\mathrm{L} / \mathrm{min}$ conversion & \\
\hline$c_{p}$ & Specific heat capacity of water & {$\left[\mathrm{J} / \mathrm{kg} \cdot{ }^{\circ} \mathrm{C}\right]$} \\
\hline$f_{i-j}$ & Water flow rate between points $i$ and $j$ & {$\left[\mathrm{~m}^{3} / \mathrm{s}\right]$} \\
\hline$H$ & Solar field global losses coefficient & $5.88\left[\mathrm{~J} / \mathrm{s} \cdot{ }^{\circ} \mathrm{C}\right]$ \\
\hline$K$ & Static gain & \\
\hline$l_{i-j}$ & Distance between points $i$ and $j$ & {$[\mathrm{~m}]$} \\
\hline$L$ & Collector absorber tube length & $1.95[\mathrm{~m}]$ \\
\hline$L_{e q}$ & Equivalent absorber tube length & {$[\mathrm{m}]$} \\
\hline$\dot{m}_{e q}$ & Equivalent solar-field mass flow rate & {$[\mathrm{kg} / \mathrm{s}]$} \\
\hline$\dot{m}_{l}$ & Load mass flow rate & {$[\mathrm{kg} / \mathrm{s}]$} \\
\hline$\dot{m}_{s f}$ & Solar field mass flow rate & {$[\mathrm{kg} / \mathrm{s}]$} \\
\hline \multirow[t]{2}{*}{$n_{c s}$} & Number of series-connections & 5 \\
\hline & in a collectors group & \\
\hline \multirow[t]{2}{*}{$n_{i-j}$} & Integer multiple for estimating & {$[-]$} \\
\hline & the delay between point $i$ and $j$ & \\
\hline$t_{d}$ & Time delay & {$[\mathrm{s}]$} \\
\hline$t_{r, i-j}$ & Transport delay between points $i$ and $j$ & {$[\mathrm{~s}]$} \\
\hline$t_{s}$ & Sampling time & {$[\mathrm{s}]$} \\
\hline \multirow[t]{2}{*}{$\overline{\mathrm{T}}$} & Equivalent absorber tube & {$\left[{ }^{\circ} \mathrm{C}\right]$} \\
\hline & mean temperature & \\
\hline$v_{i-j}$ & Velocity rate between points $i$ and $j$ & {$[\mathrm{~m} / \mathrm{s}]$} \\
\hline $\mathrm{V}_{1}$ & Volume, first stratification & $0.4\left[\mathrm{~m}^{3}\right]$ \\
\hline $\mathrm{V}_{2}$ & Volume, second stratification & $0.3\left[\mathrm{~m}^{3}\right]$ \\
\hline $\mathrm{V}_{3}$ & Volume, third stratification & $0.8\left[\mathrm{~m}^{3}\right]$ \\
\hline $\mathrm{V} 1_{\mathrm{m}}$ & Variable modeling the nonlinear & {$[\%]$} \\
\hline
\end{tabular}


behaviour of valve 1

\begin{tabular}{lll}
$\alpha_{1}$ & $\begin{array}{l}\text { Thermal losses coefficient, } \\
\text { first stratification }\end{array}$ & $3.3[\mathrm{~J} / \mathrm{s} \cdot \mathrm{K}]$ \\
$\alpha_{2}$ & $\begin{array}{l}\text { Thermal losses coefficient, } \\
\text { second stratification }\end{array}$ & $2.9[\mathrm{~J} / \mathrm{s} \cdot \mathrm{K}]$ \\
$\alpha_{3}$ & $\begin{array}{l}\text { Thermal losses coefficient, } \\
\text { third stratification }\end{array}$ & $3.3[\mathrm{~J} / \mathrm{s} \cdot \mathrm{K}]$ \\
$\beta$ & Irradiance model parameter & $0.134[\mathrm{~m}]$ \\
$\rho$ & Water density & {$\left[\mathrm{kg} / \mathrm{m}^{3}\right]$} \\
$\tau$ & Representative time constant & {$[\mathrm{s}]$} \\
\hline
\end{tabular}

Table 4: Definition of the parameters involved in the model.

\section{Control system}

The goal of the proposed hierarchical controller consists on improving the start-up procedure of the plant used as test-bed. The thermal load of the facility, as most solar-powered processes, requires a determined operating temperature to start the operation, which in this case is $60\left[{ }^{\circ} \mathrm{C}\right]$. Moreover, it should be remarked that the thermal load is connected to the fluid coming from the tank through a heat exchanger, so the temperature at the top of the tank must be even higher. Therefore, if the temperature in the tank does not allow operating the membrane distillation unit, a start-up procedure must be implemented, in which the solar field is used to increase the temperature of the tank.

Traditionally, qualified operators perform this procedure in a manual way attending to heuristic rules as the ones presented in Cirre (2007). First, when the global irradiance reaches values between $500-600\left[\mathrm{~W} / \mathrm{m}^{2}\right]$, normal range in which most solar thermal facilities are turned on (Dinter \& Gonzalez, 2014. Kolb, 2011), pump 1 is started, and the fluid is recirculated only through the solar field (i.e. with valve 1 close to the solar field). Afterwards, when a high 
temperature (such as $80\left[{ }^{\circ} \mathrm{C}\right]$ ) is reached at the outlet of the solar field, valve 1 is opened towards the tank, circulating the fluid trough it until reaching the required temperature to operate the thermal load. However, this manual procedure presents two main problems. The first one is related to the irradiance disturbances, since the operator must close valve 1 when there are severe irradiance disturbances to avoid loading the tank with cold fluid, which could be hard to perform in a manual way, especially when the disturbances are caused by passing clouds. The second problem is associated to the stratification of the storage tank. These kind of tanks are usually operated with several degrees of stratification (Duffie \& Beckman, 2013), that means that the temperature at the top of the tank is higher than in the bottom. So, depending on the degree of stratification, when performing the manual start-up procedure and opening the valve 1 to recirculate the fluid through the tank, the temperature at the outlet of the solar field can drop drastically until the tank reaches a certain degree of homogeneity. For these reasons, the manual procedure can take long time, and it requires the full attention of an operator to ensure that the tank is not being loaded with cold fluid.

The first automatic approach for improving this manual start-up procedure was developed in the previous paper Gil et al. (2018b). In that work, the steadystate model of the solar field was used to estimate the value of irradiance required to turn the solar field on for heating the tank. In addition, a predictive controller was used to calculate the setpoints at the outlet of the solar field, trying to maximize the temperature in the tank, and a cascade controller was proposed for tracking these setpoints by acting in pump 1. Thus, the problem related to the irradiance disturbances was improved, and the solar field was turned on in a more deterministic way. However, the problem related to the stratification of the tank was not considered. A second step towards the improvement of the start-up procedure was presented in Gil et al. (2018a), in which valve 1, which was fixed in open position to feed the tank in the work mentioned above, was used as control variable allowing to obtain a proper temperature at the entrance of the solar field that guarantees a minimum temperature for heating 
the tank. The control structure proposed in that work was composed of a reference governor and a multivariable controller. On the one hand, the reference governor solved an optimization problem, using the steady-state model of the solar field, aimed at maximizing the temperature at the top of the tank, guaranteeing that the temperature of the fluid flowing to the tank was higher than the one at the top of the tank. On the other hand, the multivariable controller was tasked with tracking the setpoints computed by the reference governor by acting on both pump 1 and valve 1 . Therefore, the irradiance disturbance and tank stratification problems were improved with this approach.

In the present work, the idea for improving the start-up procedure is the same that the one presented in Gil et al. (2018a), which consists on using valve 1 as a control variable for heating the tank faster. However, the control structure has been considerably improved by using a hierarchical control system composed of two layers: i) an upper layer based on a predictive controller, and ii) a regulatory layer based on PID controllers. We have opted for a hierarchical control structure (where the top layer calculates the setpoints to be tracked by the lower layer) instead of a classical optimal control structure (where the optimization directly calculates the control signals that are sent to the actuators) for two fundamental reasons: firstly, it is a more intuitive structure for the operators of the installation, allowing to maintain classic PID controllers in the regulation layer; secondly, because optimal control strategies provide very aggressive control signals, which are not adequate for this type of installation. The schematic diagram of the hierarchical structure is shown in Fig. 6. In the upper layer, the predictive controller uses the nonlinear model of the system presented in Section 3 for making the predictions and calculating the setpoints for the regulatory layer. In this way, a prediction horizon and a nonlinear model are considered in the control procedure, allowing to calculate the setpoints more accurately than in the approach proposed in Gil et al. (2018a), in which a steady-state model and static values are used for calculating the references. The regulatory layer comprises a cascade control scheme for controlling the outlet solar field temperature by acting on pump 1, and a Filtered Smith Predictor (FSP) structure for 
controlling the inlet temperature of the solar field by using valve 1 . These two control systems were also used in the two loops of the multivariable controller proposed in Gil et al. (2018a). However, in this work, the multivariable approach has not been considered due to the low interaction between the variables involved in the process, as was analyzed in Gil et al. (2018a). Moreover, the FSP controller has been improved by adding the nonlinear model of valve 1 .

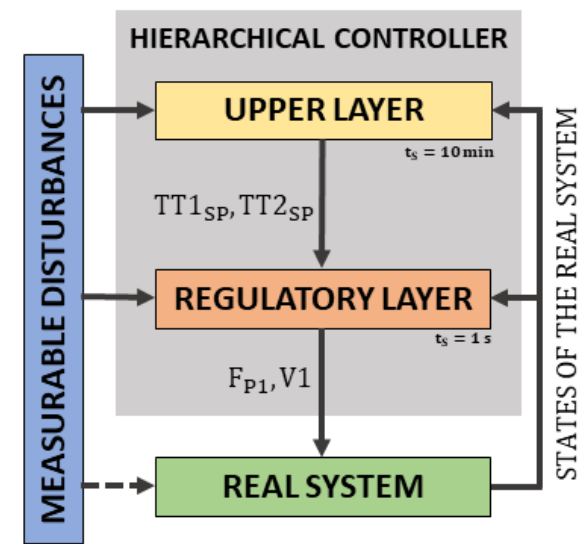

Figure 5: Schematic diagram of the hierarchical control system.

\subsection{Regulatory layer}

The PID based regulatory layer includes two loops, and its objective consists on tracking the setpoints computed by the upper layer for the two controlled variables, i.e. TT1 and TT2, as well as maintaining them near steady state conditions around these references despite temperature or irradiance disturbances.

In order to control TT2, a cascade control loop is employed (see Fig. 6). The design and test of this loop were already presented in Gil et al. (2018c). According to Fig. 6, the slave controller (PI-2) is tasked with controlling the flow rate (FT1) by using the input frequency of pump $1\left(\mathrm{~F}_{\mathrm{P} 1}\right)$, whereas the outer one (PI-1) is responsible for maintaining the desired temperature at the outlet of the solar field $\left(\mathrm{TT} 2_{\mathrm{SP}}\right)$ by acting on the flow rate (FT1 $\left.1_{\mathrm{PID}}\right)$. In addition, a 
feedforward (FF) including the steady-state model of the solar field is used for improving the disturbance rejection of the loop. Notice that at the outlet of the feedforward, a low pass filter (LPF-1) is added to achieve a better dynamical behaviour. In this way, the setpoint for the slave loop $\left(\mathrm{FT}_{\mathrm{SP}}\right)$, is calculated taking into account the contributions of the feedforward $\left(\mathrm{FT} 1_{\mathrm{FF}}\right)$ and the outer loop (FT1 1 PID $)$, as well as the feedback. Finally, a low pass filter (LPF-2) is also included in the reference for reducing overshoots against reference step changes. The parameters of each of the blocks of this loop are shown in Table 5 .

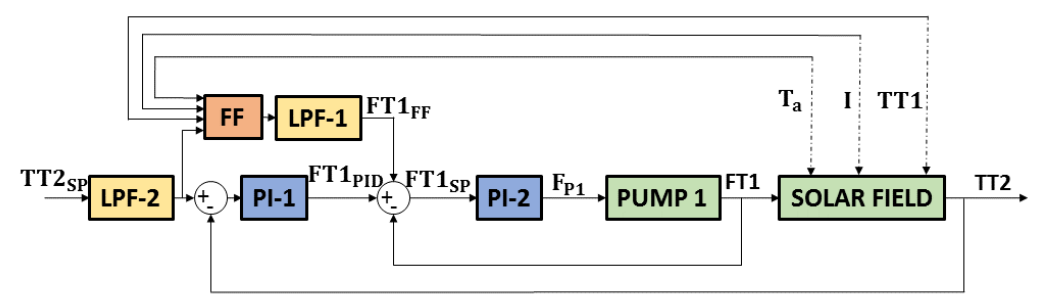

Figure 6: Schematic diagram of the outlet solar field temperature controller.

The second loop is used for controlling TT1 by acting on the Valve 1 aperture (V1). In this loop, a FSP structure is adopted Normey-Rico \& Camacho (2007). This structure is appropriate for the problem at hand, since the nominal delay of the process $(79[\mathrm{~s}])$ is dominant with respect to the characteristic time constant (43 [s]), see Section 3 . In addition, there are modeling dead-time errors due to the transport delays caused by the variations of the flow rate, which degrades performance and can cause instability. In this way, the FSP approach adds robustness to the controller (Normey-Rico \& Camacho, 2007), enabling to achieve the desired performance. The schematic diagram of the controller is shown in Fig. 7 Notice that the configuration of this loop was presented in Gil et al. (2018a). However, in the present approach, a modification is introduced by including the nonlinear model of valve 1 and the mix produced in it, Eqs. 3, 4, and 5, in the fast model of the FSP structure. These static 
equations allow us to calculate TT1 taking into account the nonlinear characteristics of Valve 1, thus improving the control performance. Besides, a low pass filter (LPF-4) with the dynamic obtained at the medium operating range of V1 is used to complete the fast model and compute the predicted value of inlet temperature after the delay $\mathrm{TT} 1\left(t+t_{d}\right)$. For modelling the time delay $\left(t_{d}\right)$, the nominal error model shown in Table 3 has been used. Moreover, the filter of the SP structure (LPF-5) has been designed taking into account the variations between the maximum and minimum dead times observed in the system and the selected nominal dead time. These differences are around $\pm 25[\%]$, so the time constant of the filter can be computed as $\tau_{F}=0.5 \cdot t_{d}$, according to the recommendations given in Normey-Rico \& Camacho (2007). It should be remarked that the reference $\left(\mathrm{TT} 1_{\mathrm{SP}}\right)$ is filtered by means of a low pass filter $(\mathrm{LPF}-3)$. The parameters of the controller are also presented in Table 5.

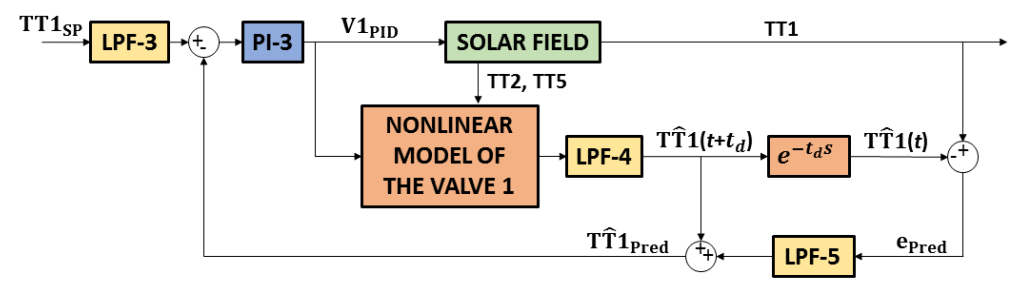

Figure 7: Schematic diagram of the inlet solar field temperature controller.

Finally, it should be remarked that an antiwindup scheme is included in each of the control loops. The operating limits of each of the control variables are 10-90 [\%], 7.5-20 [L/min], and 20-80 [\%] for pump $1\left(\mathrm{~F}_{\mathrm{P} 1}\right)$, water flow rate (FT1) and valve 1 (V1) respectively. Notice that with frequencies lower than $10[\%]$ the pump is turned off. Both controllers have been implemented with a sampling time of $1[\mathrm{~s}]$, which was chosen according to the fastest representative time constant of the variables involved in the loops, which is the one of the transfer function relating the flow rate and the pump frequency (see Table 3). 


\begin{tabular}{cccc}
\hline Block & $\mathrm{k}_{c}$ & $\mathrm{~T}_{i}[\mathrm{~s}]$ & $\tau_{F}[s]$ \\
\hline LPF-1 & - & - & 75 \\
LPF-2 & - & - & 60 \\
LPF-3 & - & - & 40 \\
LPF-4 & - & - & 43 \\
LPF-5 & - & - & 39.50 \\
PI-1 & $-0.42\left[\mathrm{~L} / \mathrm{min} \cdot{ }^{\circ} \mathrm{C}\right]$ & 72.60 & - \\
PI-2 & $2.84[\% \cdot \min / \mathrm{L}]$ & 4.92 & - \\
PI-3 & $14.01\left[\% /{ }^{\circ} \mathrm{C}\right]$ & 43 & - \\
\hline
\end{tabular}

Table 5: Parameters of controller blocks of the regulatory layer. $\mathrm{k}_{c}$ and $\mathrm{T}_{i}$ are the proportional gain and integral time of the Proportional Integral (PI) controller, and $\tau_{F}$ the characteristic time constant of the low pass filters. Notice that the PI controllers have been implemented using the ideal PID transfer function.

\subsection{Upper layer}

This layer is in charge of calculating the setpoints, $\mathrm{TT} 1_{\mathrm{SP}}$ and $\mathrm{TT} 2_{\mathrm{SP}}$, for the regulatory layer, trying to increase TT3 faster, so that the operational time of the facility is maximized. The control methodology chosen for developing this layer is the MPC technique. This advanced control strategy is one of the most generic ways of formulating a control problem, and it has been selected because it intrinsically deals with the main problems presented in the facility used in this work, mainly long time delays and disturbances (Camacho \& Bordons, 2004). Besides, this control technique has been already applied in solar thermal fields with satisfactory results (De Andrade et al., 2015, Gallego et al., 2019)

There are different algorithms in the family of MPC controllers, however, the basis of all of them are the same:

1. use of a system model to compute the prediction of the process output in a prediction horizon;

2. formulation of an optimization problem to calculate the control sequence along the control horizon; and 
3. use of a receding strategy, displacing at each sampling time the horizon towards the future, and applying in the actual system only the first control signal of the set computed at each step.

Their differences are due to the model that they use for representing the system and the noises, as well as the cost function that must be minimized. In this work, as the model of the facility is nonlinear, an MPC algorithm able to cope with this kind of models must be chosen. Thus, the Practical Nonlinear Model Predictive Control (PNMPC) algorithm is used due to the several advantages that it presents with respect to other nonlinear MPC techniques (Plucenio et al. 2007 ) as: i) it can cope with different nonlinear model structures, ii) it is simple to compute, and iii) it does not use iterative algorithms for linearizing the process model. In addition, it has been already tested in other nonlinear processes with successful results Andrade et al., 2013, Castilla et al. 2014, Gil et al. $2018 b$ ).

\subsubsection{PNMPC algorithm}

In MPC techniques, the prediction of the output process variable $\hat{\mathbf{Y}}$, in a determined prediction horizon $N$, is calculated in a vectorial form as:

$$
\hat{\mathbf{Y}}=\mathbf{f}+\mathbf{G} \cdot \Delta \mathbf{u}
$$

where $\hat{\mathbf{Y}}=[\hat{\mathrm{Y}}(t+1 \mid t), \hat{\mathrm{Y}}(t+2 \mid t) \ldots \hat{\mathrm{Y}}(t+N \mid t)]^{T} \mathbb{1}, \mathbf{f}=[\hat{\mathrm{f}}(t+1 \mid t), \hat{\mathrm{f}}(t+2 \mid t) \ldots \hat{\mathrm{f}}(t+$ $N \mid t)]^{T}, \Delta \mathbf{u}=\left[\Delta u(t \mid t), \Delta u(t+1 \mid t) \ldots \Delta u\left(t+N_{u}-1 \mid t\right)\right]^{T}, N_{u}$ being the control horizon. $\mathbf{f}$ is known as free response whereas $\mathbf{G} \cdot \Delta \mathbf{u}$ is called forced response and $\Delta \mathbf{u}$ is the future control increment. As was previously mentioned, one of the differences among MPC algorithms is the way in which the free response f and the step response matrix $\mathbf{G}$ are calculated. In linear systems, they can be easily computed based on the superposition principle (Camacho \& Bordons, 2004). However, in nonlinear processes, the superposition principle does not

\footnotetext{
${ }^{1}$ The nomenclature $\hat{\mathrm{x}}(\mathrm{t}+k \mid t)$ refers to the value of $\hat{\mathrm{x}}$ at discrete instant time $\mathrm{t}+k$, computed with the information acquire up to instant $t$.
} 
hold, and an approximation for calculating $\hat{\mathbf{Y}}$ must be performed. The strategy for estimating $\hat{\mathbf{Y}}$ using the PNMPC algorithm (Plucenio et al., 2007) is given by:

$$
\begin{array}{r}
\hat{\mathbf{Y} \approx} \mathbf{f}+\mathbf{G}_{\mathrm{PNMPC}} \cdot \Delta \mathbf{u} \\
\mathbf{f}=f(\overleftarrow{\mathbf{Y}}, \Delta \overleftarrow{\mathbf{u}}, \Delta \overleftarrow{\mathbf{v}}) \\
\mathbf{G}_{\text {PNMPC }}=\frac{\partial \hat{\mathbf{Y}}}{\partial \Delta \mathbf{u}}
\end{array}
$$

where $f(\cdot)$ is a function of its arguments, $\overleftarrow{\mathbf{Y}}$ is a set of past and present process outputs, $\Delta \overleftarrow{\mathbf{u}}$ is a set of past increments in the inputs, $\Delta \overleftarrow{\mathbf{v}}$ is a set of past increments in the measurable disturbances, $\mathbf{f}$ is the vector of predictions provided by the nonlinear model obtained with $\Delta \mathbf{u}=0$, and $\mathbf{G}_{\mathbf{P N M P C}}$ is the jacobian matrix computed in the current point $u$. To compute both $\mathbf{f}$ and $\mathbf{G}_{\mathbf{P N M P C}}$, the procedure presented in Plucenio et al. (2007) and described in Algorithm 1 must be used. Note that, although this technique is only an approximation, it provides better results than if a linear model were used, since $\mathbf{f}$ is directly calculated with the nonlinear model of the process, while $\mathbf{G}_{\mathbf{P N M P C}}$ is computed by linearizing the model around the trajectory, thus allowing this technique to consider the nonlinearity along the prediction horizon (Plucenio et al., 2007).

Following the formulation of the proposed control system, the PNMPC strategy is employed in this work to make the prediction of the top tank temperature, $\hat{\mathbf{Y}}_{\mathbf{T T 3}}$, as a function of the increments in the setpoints of the loops included in the regulatory layer $\left(\Delta \mathbf{T} \mathbf{T} \mathbf{1}_{\mathbf{S P}}\right.$ and $\left.\Delta \mathbf{T T} \mathbf{2}_{\mathbf{S P}}\right)$, that according to the PNMPC procedure is:

$$
\begin{array}{r}
\hat{\mathbf{Y}}_{\mathbf{T T} 3} \approx \mathbf{f}_{\mathbf{T T} 3}+\left[\mathbf{G}_{\mathbf{P N M P C}-1} \mathbf{G}_{\mathbf{P N M P C}-2}\right] \cdot\left[\Delta \mathbf{T T} 1_{\mathbf{S P}} ; \Delta \mathbf{T T} 2_{\mathbf{S P}}\right] \\
\mathbf{f}_{\mathbf{T T} 3}=f\left(\overleftarrow{\mathbf{Y}}_{\mathbf{T T} 3}, \Delta \overleftarrow{\mathbf{T T}} 1_{\mathbf{S P}}, \Delta \overleftarrow{\mathbf{T T} 2} \mathbf{S P}_{\mathbf{S P}}, \Delta \overleftarrow{\mathrm{v}}\right) \\
\mathbf{G}_{\mathbf{P N M P C}-1}=\frac{\partial \hat{\mathbf{Y}}_{\mathbf{T T} 3}}{\partial \Delta \mathbf{T T} 1_{\mathrm{SP}}}, \\
\mathbf{G}_{\mathbf{P N M P C}-2}=\frac{\partial \hat{\mathbf{Y}}_{\mathbf{T T} 3}}{\partial \Delta \mathbf{T T} \mathbf{S P}_{\mathrm{SP}}},
\end{array}
$$

where $\overleftarrow{\mathbf{Y}}_{\text {TT3 }}$ is a set of past and present values of TT3, $\Delta \overleftarrow{\mathbf{T T} 1}_{\text {SP }}$ is a set of past values of input $\Delta \mathrm{TT} 1_{\mathrm{SP}}$, and $\Delta \overline{\mathbf{T T} 2}_{\mathrm{SP}}$ is a set of past values of input $\Delta \mathrm{TT} 2_{\mathrm{SP}}$. 
Algorithm 1: Method to compute F and $\mathbf{G}_{\mathbf{P N M P C}}$

1. To calculate $\hat{\mathbf{Y}}^{0}$, which is a vector of length $N$, the model must be executed with past measurable disturbances, outputs, and inputs with $\Delta \mathbf{u}=\left[\begin{array}{lll}0 & 0 \ldots 0\end{array}\right]^{T}$. So that, $\mathbf{F}=\hat{\mathbf{Y}}^{0}$.

2. To calculate the first column of $\mathbf{G}_{\mathbf{P N M P C}} \cdot \hat{\mathbf{Y}}^{1}$ is computed as stated in the step above, but with $\Delta \mathbf{u}=[\epsilon 0 \ldots 0]^{T}$, where $\epsilon$ is a little increment in the control action, i.e. $\frac{u(k-1)}{1000} \cdot \mathbf{G}_{\mathbf{P N M P C}}(:, 1)=\frac{\hat{\mathbf{Y}}^{1}-\hat{\mathbf{Y}}^{0}}{\epsilon}$.

3. To compute the second column of the $\mathbf{G}_{\mathbf{P N M P C}}, \hat{\mathbf{Y}}^{2}$ is calculated with $\Delta \mathbf{U}=\left[\begin{array}{lll}0 & \epsilon \ldots 0\end{array}\right]^{t} . \mathbf{G}_{\mathbf{P N M P C}}(:, 2)=\frac{\hat{\mathbf{Y}}^{2}-\hat{\mathbf{Y}}^{0}}{\epsilon}$.

4. The same method as in the two previous steps must be repeated until completing the remaining columns of matrix $\mathbf{G}_{\mathbf{P N M P C}}$. It should be remarked that the number of columns of $\mathbf{G}_{\mathbf{P N M P C}}$ is given by the control horizon $N_{u}$, so the last column is computed as:

$\mathbf{G}_{\mathbf{P N M P C}}\left(:, N_{u}\right)=\frac{\hat{\mathbf{Y}}^{N_{u}}-\hat{\mathbf{Y}}^{0}}{\epsilon}$.

It should be remarked that the main disturbances that affect to the facility are the irradiance and the ambient temperature ones, so that $\Delta \overleftarrow{\mathrm{v}}$ is composed by a set of past increments of these two variables.

\subsubsection{Treatment of the disturbances and prediction errors}

As in other MPC techniques, the PNMPC strategy completes the predictions including a model for taking into account disturbances and prediction errors. This model is given by:

$$
\begin{array}{r}
\boldsymbol{\Lambda}=\mu(t) \cdot \mathbf{1}_{N \times 1}, \\
\Delta \mu(t)=\frac{\phi}{\Omega}(\mathrm{Y}(t)-\hat{\mathrm{Y}}(t)),
\end{array}
$$

where 1 is a vector of length $N \times 1, \phi$ and $\Omega$ (which includes an integrator) are the numerator and denominator respectively of a discrete time filter, and $\mathrm{Y}(t)-\hat{\mathrm{Y}}(t)$ is the error between the actual output value and the predicted one. This method is comparable to the CARIMA model (Camacho \& Bordons, 
2004). The intention is to add the integral of the filtered prediction error to each predicted process output. (Eq. (18)). The numerator and denominator of the discrete time filter are normally considered as design parameters. The most popular structure of this filter is $\phi\left(q^{-1}\right) / \Omega\left(q^{-1}\right)=1 /\left(1-q^{-1}\right)$, where $q^{-1}$ is the backwards shift operator. However, the robustness of the disturbance model can be improved by considering the numerator as $\phi\left(q^{-1}\right)=1-a \cdot q^{-1}$, with $0 \ll a \leq 1$ (De Keyser \& Ionescu, 2003). In this way, the structure used in this work is given by $\phi\left(q^{-1}\right) / \Omega\left(q^{-1}\right)=\left(1-a \cdot q^{-1}\right) /\left(1-q^{-1}\right)$.

\subsubsection{Objective function}

The set of control actions is computed by minimizing an objective function $(\mathrm{J})$. In this case, the aim of the control procedure is to maximize the temperature at the top of the storage tank (TT3). Therefore, the first term of the objective function is aimed at maximizing the predictions of this variable, $\hat{\mathrm{Y}}_{\mathrm{TT} 3}(t+k \mid t)$ along the prediction horizon $N$, which means $\forall k \in 1, \ldots, N$. Besides, a second term has been added to penalize the variations in the control actions, $\Delta \mathrm{TT} 1_{\mathrm{SP}}(t+k-1)$ and $\Delta \mathrm{TT} 2_{\mathrm{SP}}(t+k-1)$, along the control horizon $N_{u}$, that is $\forall k \in 1, \ldots, N_{u}$ (to avoid aggressive control actions):

$\mathrm{J}=-\sum_{k=1}^{k=N} \hat{\mathrm{Y}}_{\mathrm{TT} 3}(t+k \mid t)+\lambda \cdot \sum_{k=1}^{k=N_{u}}\left(\left|\Delta \mathrm{TT} 1_{\mathrm{SP}}(t+k-1)\right|+\left|\Delta \mathrm{TT} 2_{\mathrm{SP}}(t+k-1)\right|\right)$

where $\lambda$ is a weighting factor. In the problem at hand, the two control actions have the same importance in the optimization problem, thus only one $\lambda$ was used in $\mathrm{J}$.

\subsubsection{Constraints}

The optimization problem is subjected to several constraints which are defined according to the process requirements. As the fluid flowing through the pipes of the solar field is water, the temperature must be lower than $100\left[{ }^{\circ} \mathrm{C}\right]$ to avoid vapour formation during the operation:

$$
\mathrm{TT} 2(t+k-1)<100 \forall k \in 1, \ldots, N_{u},
$$


In addition, TT2 cannot be lower than TT1, neither lower than TT3 to avoid cooling down the tank:

$$
\begin{array}{r}
\operatorname{TT} 2(t+k-1)>\operatorname{TT} 1(t+k-1) \forall k \in 1, \ldots, N_{u}, \\
\operatorname{TT} 2(t+k-1)>\hat{\mathrm{Y}}_{\mathrm{TT} 3}(t+k \mid t) \forall k \in 1, \ldots, N_{u},
\end{array}
$$

Finally, the outlet temperature of the solar field can vary between the maximum and minimum temperature reachable at each instant, $\mathrm{TT} 2_{\max }$ and $\mathrm{TT} 2_{\min }$ respectively. These limits can be calculated using the model of the solar field (Eq. (1)) in steady-state conditions as was done in Gil et al. (2018b), according to the operating conditions (i.e global irradiance level, ambient temperature, inlet solar field temperature) and the maximum and minimum water flow rate, $\mathrm{FT} 1_{\max }$ and $\mathrm{FT} 1_{\min }$ repectively:

$\mathrm{TT} 2_{\min }(t+k-1 \mid t)=f\left(\mathrm{I}(t), \mathrm{T}_{a}(t), \operatorname{TT} 1(t+k-1), \mathrm{FT} 1_{\max }\right) \forall k \in 1, \ldots, N_{u}$,

$\mathrm{TT} 2_{\max }(t+k-1 \mid t)=f\left(\mathrm{I}(t), \mathrm{T}_{a}(t), \mathrm{TT} 1(t+k-1), \mathrm{FT}_{\text {min }}\right) \forall k \in 1, \ldots, N_{u}$.

Note that the irradiance and ambient temperature are kept constant along the prediction horizon to compute the equations formulated above. It was tested that maintaining irradiance constant, the results obtained are comparable to those obtained if a prediction technique such as the one proposed in Pawlowski et al. (2011) were applied, due to the low reliability of these kind of techniques. Thus, the constraint can be formulated as:

$\mathrm{TT} 2 \min _{\min }(t+k-1 \mid t) \leq \mathrm{TT} 2(t+k-1) \leq \mathrm{TT} 2_{\max }(t+k-1 \mid t) \forall k \in 1, \ldots, N_{u} .(26)$

\subsection{Procedure to turn on the hierarchical controller}

The procedure to turn on the hierarchical controller is divided in two phases. In the first one, as it was done in Gil et al. (2018b), the steady-state model of the solar field is used to calculate the value of global irradiance required to start-up the solar field. By using this model, the value of global irradiance can be calculated as:

$$
\mathrm{I}_{\mathrm{th}}(t)=f\left(\mathrm{FT} 1_{\max }(t), \mathrm{TT} 1(t), \mathrm{TT} 2(t), \mathrm{T}_{a}(t)\right) .
$$


To consider the operating conditions of the tank when calculating this value, $\mathrm{TT} 2(t)$ has been fixed at the same value than the top tank temperature TT3 $(t)$. In the same way, as the fluid is initially recirculated only through the solar field when starting the operation (see the second phase to turn on the solar field), $\operatorname{TT} 1(t)$ is set to a degree below TT2 $(t)$ to consider thermal losses in the pipes. In addition, the water flow rate was fixed at its maximum operating

range. To choose this value several simulation tests were carried out checking this procedure with the maximum and minimum water flow rate. These tests showed that by using the minimum range, the required global irradiance is lower, however, if there is cold fluid in the pipes, the time that the fluid must be recirculated through the solar field for reaching the tank temperature is higher.

In the second phase, once the actual global irradiance value reaches the calculated one, i.e. $\mathrm{I}_{\mathrm{th}}(t) \leq \mathrm{I}(t)$, the fluid is only recirculated trough the solar field until reaching the tank temperature, time instant in which the hierarchical control system is turned on. Also note that, in order to avoid chattering problems, the conditions are checked with mean values of the last five minutes instead of instant ones.

\section{Results and discussion}

A simulation and an experimental campaign were carried out for evaluating the proposed approach. The controller was implemented in MATLAB 2018a, using the YALMIP toolbox (Löfberg, 2004) and the fmincon solver (MATLAB, 2018). Regarding the controller set-up, the sampling time of the lower layer was fixed at $1 \mathrm{~s}$, which was chosen taken into account the fastest representative time constant of the variables involved in the loops, as mentioned above. The sampling time of the upper layer was fixed at $10 \mathrm{~min}$, which was selected according to the settling time of the lower layer controllers (around $8 \mathrm{~min}$ ). The prediction horizon $N$ and the control horizon $N_{u}$ were set to 5 and 1 , respectively. These values were selected taking into account traditional recommendations in MPC controllers, $N$ large enough to contemplate the transient part of the response, 
and $N_{u} \ll N$. Finally, $\lambda$ and $a$ were fixed at 0.2 and 0.8 respectively, which were selected after exhaustive simulations until obtaining the desired closed loop response.

In what follows: i) the implementation of the approach in the real facility and the results obtained with the application of the controller are presented, and ii) a comparison among the results obtained in simulation with the approach presented in this paper, with a manual operation, and with the strategies proposed in Gil et al. (2018b) and Gil et al. (2018a) is shown.

\subsection{Implementation of the algorithm in the real facility and experimental results}

Due to an anomalous behaviour in the operation of the expansion vessel of the solar field, the control algorithm had to be slightly modified for doing the experimental tests. Note that this behaviour should not occur, and it is an exception that happens only in this plant. So that, for applying the algorithm in other facilities, it must be implemented as has been described above.

An open-loop test is shown in Fig. 8 to visualize the effect that gives rise to this this anomalous behaviour. As can be seen, when a positive or a negative change is applied in the flow rate, the inlet temperature of the solar field drastically drops, and then, it is quickly restored, causing an undesired transient in TT1 that can produce oscillations and even instability during the automatic operation. Conversely, it can be observed that this transient is filtered by the solar field, and therefore, it does not affect TT2. Note that when the flow rate is decreased the pressure also decreases, and part of the water remaining in the expansion vessel comes out momentarily cooling the entrance of the circuit. When the flow rate is increased and due to the underdamped behavior of the pump (see the last change in Fig. 8), there is also a small pressure drop, and again, water from the expansion vessel comes out. It should be remarked that an attempt has been made to model this phenomenon, but it has been impossible both with models based on first principles and with empirical models, since the temperature drop has no recognizable patterns.

Thus, to avoid feeding back the controllers with the actual TT1 during 

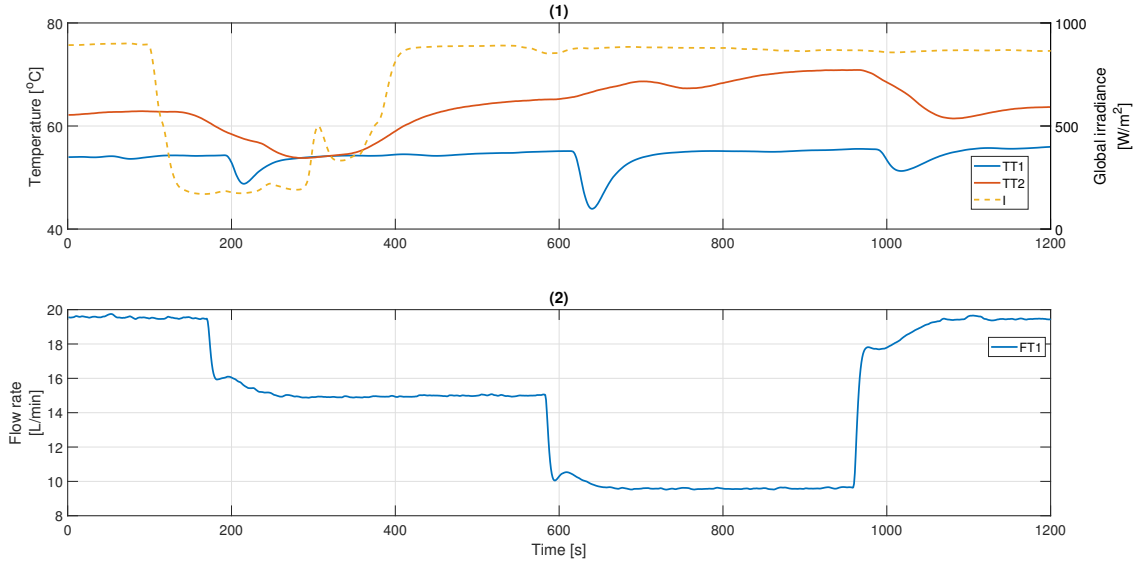

Figure 8: Illustrative open loop test. (1) Inlet temperature of the solar field (TT1), outlet temperature of the solar field (TT2), and global irradiance (I), and (2) solar field water flow rate $(\mathrm{FT} 1)$.

these transients, experimental tests were carried out to find both the maximum duration of this transitory effect when a change in the flow rate is applied, and the minimum ramp change in the flow rate that causes them. In this way, it was experimentally tested that, in the worst case, the maximum time was $140[\mathrm{~s}]$, whereas flow rates with slopes lower than 8 [\%] do not affect the inlet temperature.

Once these two issues were characterized, a decision maker was designed to decide if the control loops that require TT1, see Figs. 6 and 7, are fed back with the real temperature or with an estimated temperature calculated with the model (see Eq. (3p)). The schematic diagram of the decision maker is presented in Fig. 9. The inputs of the block are the solar field water flow rate (FT1), the actual inlet solar field temperature (TT1), and the temperature calculated by Eq. (3) $\left(\mathrm{TT}_{m}\right)$. If the slope of the flow rate is less than 8 [\%], the output of the block $\left(\mathrm{TT} 1_{\text {feedback }}\right)$ is the actual TT1, whereas if the slope is higher than this value, the output is $\mathrm{TT} 1_{m}$ during $140[\mathrm{~s}]$. It should be remarked that for doing the transitions between $\mathrm{TT} 1$ and $\mathrm{TT} 1_{m}$, a low pass filter is used with a characteristic time constant of 15 [s], thus avoiding discontinuities. 


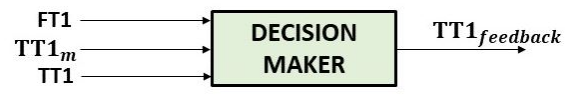

Figure 9: Decision maker.

Next step was to test the control system in the real facility. Several experiments with different temperature initial conditions in the storage tank were performed in order to evaluate the hierarchical controller. Fig. 10 shows one representative test carried out on the day 15 March, 2019. In this test, the initial temperatures in the tank were $58,50.6$, and $47.6\left[{ }^{\circ} \mathrm{C}\right]$ for TT3, TT4 and TT5 respectively. It should be remembered that the temperature at the top of the tank must be higher than $60\left[{ }^{\circ} \mathrm{C}\right]$ for operating the thermal load. So, with these conditions, the tank was unloaded in terms of thermal energy, and therefore, the start-up procedure had to be carried out. In addition, it should be remarked that the degree of stratification was high, what made the automatic operation even more difficult.

The operation was started around $9.00 \mathrm{pm}$. As stated in Section 4.3. first, the algorithm calculated the value of global irradiance that allowed to start-up the solar field for heating the tank. Then, the algorithm verified at each sample time the actual value of irradiance, and when it reached the calculated one, the second phase was initialized. In the second phase, pump 1 was turned on with valve 1 closed towards the solar field, i.e. the fluid was recirculated trough the solar field. This phase was used to avoid turning on the hierarchical controller during the temperature transients produced by the cold fluid stored in the pipes. Finally, when the outlet temperature of the solar field reached the one at the top of the tank, the hierarchical controller was turned on. Thus, in the test, the calculated value of irradiance was $407.9\left[\mathrm{~W} / \mathrm{m}^{2}\right]$, which was reached around $9.28[\mathrm{~h}]$, time instant in which the second phase was started. As can be seen in Fig. 10 (2), this second phase was prolonged around 12 [min], until TT2 reached the value of TT3 around $9.49[\mathrm{~h}]$.

When the second phase was completed, the hierarchical controller was turned 

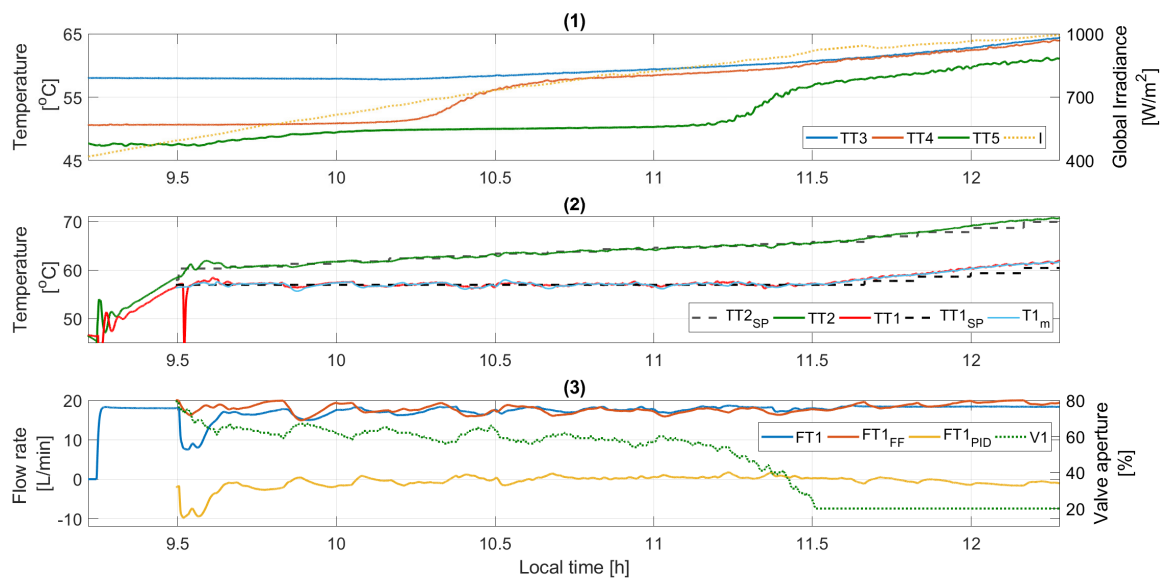

Figure 10: Experimental tests. (1) Tank temperatures (TT3, TT4 and TT5) and global irradiance (I), (2) inlet and outlet temperatures of the solar field (TT1 and TT2), setpoints $\left(\mathrm{TT} 1_{\mathrm{SP}}\right.$ and $\left.\mathrm{TT} 2_{\mathrm{SP}}\right)$ and temperature calculated by the decision maker $\mathrm{TT} 1_{\text {feedback }}$, and (3) control signals of the outlet solar field temperature control loop (FT1, FT1 $1_{\mathrm{FF}}$ and FT1 $1_{\mathrm{PID}}$ ) and control signal of the inlet solar field temperature control loop (V1).

on. The first setpoints calculated by the upper layer for each of the control loops were 60.34 and $56.54\left[{ }^{\circ} \mathrm{C}\right]$, for $\mathrm{TT} 2_{\mathrm{SP}}$ and $\mathrm{TT} 1_{\mathrm{SP}}$ respectively. As TT2 was below its reference, the lower layer controller decreased the flow rate. It is important to observe that flow decrease caused TT1 to drop as a result of the anomalous behaviour of the expansion vessel commented before. Nevertheless, thanks to the performance of the decision maker, the controllers were fed back with an estimated value obtained with the model during this period, see Fig. 10 (2).

As can also be seen in Fig. 10,(2), to maximize TT3, the upper layer maintained the setpoint of TT1 around the same value, while increased TT2 setpoint according to the irradiance conditions. This fact was specially significant for the inlet solar field temperature control loop, since if TT2 increases, for maintaining TT1 around a determined value, the controller has to gradually open valve 1 to mix the fluid coming from the solar field with the one in the bottom of the tank, which is colder. In the test, this procedure can be observed in Fig. 10-(3) between 9.49 and $11.50[\mathrm{~h}]$. This gradual opening of the valve allowed to extract 
cold fluid from the tank, heating it through the solar field, and introducing it at the upper part of the tank in a controlled way, thus decreasing the stratification of the tank and increasing its temperature, see Fig. 10.(1).

Regarding the lower layer controllers, first, the TT1 controller tracked the references correctly, performing the operation mentioned in the previous paragraph until instant time $11.50[\mathrm{~h}]$, moment in which the valve was totally opened (see Fig. 10-(3)). Second, the TT2 controller also tracked the references properly, and as can be seen, the feedforward was in charge of providing the nominal flow rate, what caused the PID signal to be always around zero except in some transients. Note that from $11.50[\mathrm{~h}]$, the actuators were saturated and small tracking errors can be observed.

\subsection{Comparison with other control strategies and a manual operation}

In order to evaluate the benefits achieved by using the proposed hierarchical control approach, its performance was compared with an operation using the manual procedure and the strategies proposed in Gil et al. (2018b) and Gil et al. (2018a). This comparison was carried out in simulation so that all methodologies have the same operating conditions. Real meteorological data from PSA (see Fig. 11) were used on the day March 8, 2017. In addition, the initial temperatures of the tank were $58,50.6$, and $47.6\left[{ }^{\circ} \mathrm{C}\right]$ for TT3, TT4 and TT5 respectively, as in the experimental test shown in the previous section.

For doing the comparison, the time taken to reach $65\left[{ }^{\circ} \mathrm{C}\right]$ from the beginning of the simulation was measured for each one of the start-up methodologies. As can be seen in Fig. 11 the simulations started at 7.00 am. However, each methodology turned on the solar field according to its start-up policy. The strategies proposed Gil et al. (2018b) and Gil et al. (2018a) and the hierarchical controller turned on the solar field when the irradiance reached $408.2\left[\mathrm{~W} / \mathrm{m}^{2}\right]$. Note that the level is almost the same that in the experimental test shown in the previous section since the tank temperature conditions, which have higher influence in this calculation, are the same. Conversely, the level for turning on the solar field in the manual procedure was fixed at $550\left[\mathrm{~W} / \mathrm{m}^{2}\right]$, medium level 
of the range in which qualified operators turn on the solar field in this kind of plants (see Section 4). It should be remarked that the manual operation was programmed as described in Section 4.

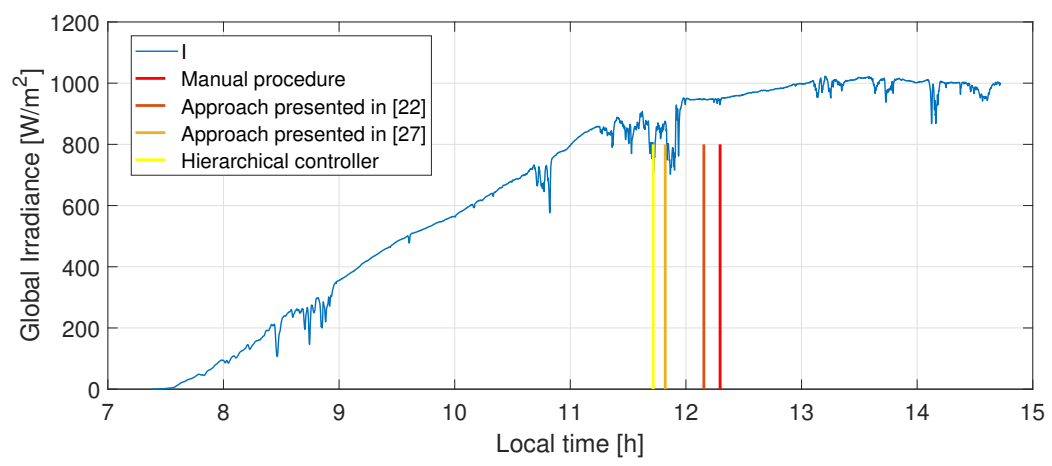

Figure 11: Global irradiance data used in the simulations, and time in which the temperature $65\left[{ }^{\circ} \mathrm{C}\right]$ was reached at the top of the tank with each one of the start-up procedures.

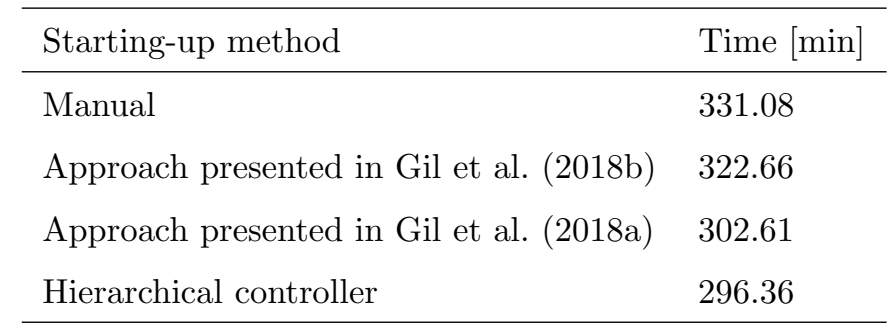

Table 6: Time in reaching $65\left[{ }^{\circ} \mathrm{C}\right]$ at the top of the tank with each one of the approaches.

Thus, the results can be analytically and graphically seen in Table 6 and Fig. 11 respectively. The operation that takes more time to reach the determined temperature was the manual one, with a time of 331.08 [min]. This is due to the difficulty in performing this operation when the tank has a high degree of stratification, and also when there are disturbances in the irradiance during the start phase as happened in this test. The operation carried out with the strategy presented in Gil et al. (2018b) took a time of 322.66 [min]. Note that in this strategy the flow rate is used to control TT2 and therefore it is able to reject irradiance disturbances, thus improving the results obtained with 
the manual operation. However, this operation has problems if the tank is stratified since the valve is not used as control variable. In this way, it can be seen that the time is clearly less with the strategies that use the valve as control variable, since they can cope with both the irradiance disturbance and the tank stratification problems. The strategy proposed in Gil et al. (2018a) required 302.61 [min] for reaching the reference temperature in the tank, whereas the proposed hierarchical controller took 296.36 [min]. This improvement is mainly due to the fact of taking into account a prediction horizon in the upper layer instead of using a static optimization problem. In addition, it should be reamarked that this improvement is achieved without adding much calculation effort, as there is not much difference between solving the optimization problem formmulated in Gil et al. (2018a) and the proposed in this paper; which is based on a PNMPC controller.

\section{Conclusions}

This paper shows an optimal real-time predictive control methodology for starting-up solar thermal fields with direct storage configuration. The methodology is based on a hierarchical controller including an MPC based layer and a regulatory one composed of PID controllers. Real experimental tests in a pilot plant with single-tank with direct storage configuration located at PSA are shown. In addition, a simulated comparative analysis with other techniques already proposed in the literature and with a manual operation is presented.

The results evidence how the proper use of a control algorithm that takes into consideration irradiance disturbances and operating conditions at each sample time can considerably reduce the time spent in the start-up procedure. This fact is especially notable when there is a big degree of stratification in the storage tank. The comparison carried out shows how the proposed controller can reduce the start-up procedure in 34 min with respect to a manual operation, and in 26 [min] if a controller that acts only over the flow rate were used. This improvement is due to the use of the mixing valve as control variable apart 
from the water flow rate (typical control variable in solar thermal fields), which allows the controller to cope with both the irradiance disturbance and temperature stratification problems during the start-up phase. Note that although the procedure has been tested in a low concentration solar field, it could also be used in medium and high concentration solar thermal plants (with parabolic trough collectors or solar towers) using a similar layout with thermal storage.

\section{Acknowledgements}

This work has been funded by the National $\mathrm{R}+\mathrm{D}+\mathrm{i}$ Plan Project DPI201785007-R of the Spanish Ministry of Science, Innovation and Universities and ERDF funds. Julio E. Normey-Rico thanks CNPq under project 305785/2015-0 for finnancial support.

\section{References}

Abid, M., Yousef, B., Assad, M., Hepbasli, A., \& Saeed, K. (2018). An experimental study of solar thermal system with storage for domestic applications. Journal of Mechanical Engineering and Sciences, 12, 4098-4116.

Andrade, G., Pagano, D., Álvarez, J., \& Berenguel, M. (2013). A practical NMPC with robustness of stability applied to distributed solar power plants. Solar Energy, 92, 106-122.

Artur, C., Neves, D., Cuamba, B. C., \& Leão, A. J. (2018). Comparison of two dynamic approaches to modelling solar thermal systems for domestic hot water. Sustainable Energy Technologies and Assessments, 30, 292-303.

Berenguel, M., Cirre, C. M., Klempous, R., Maciejewski, H., Nikodem, M., Nikodem, J., Rudas, I., \& Valenzuela, L. (2005). Hierarchical control of a distributed solar collector field. In International Conference on Computer Aided Systems Theory (pp. 614-620). Springer. 
Biencinto, M., Bayón, R., Rojas, E., \& González, L. (2014). Simulation and assessment of operation strategies for solar thermal power plants with a thermocline storage tank. Solar Energy, 103, 456-472.

Camacho, E., \& Gallego, A. (2013). Optimal operation in solar trough plants: A case study. Solar Energy, 95, 106-117.

Camacho, E. F., \& Bordons, C. (2004). Model predictive control. SpringerVerlag Ltd, London.

Casati, E., Casella, F., \& Colonna, P. (2015). Design of CSP plants with optimally operated thermal storage. Solar Energy, 116, 371-387.

Casella, F., Casati, E., \& Colonna, P. (2014). Optimal operation of solar tower plants with thermal storage for system design. IFAC Proceedings Volumes, $47,4972-4978$.

Castilla, M., Álvarez, J., Normey-Rico, J., \& Rodríguez, F. (2014). Thermal comfort control using a non-linear MPC strategy: A real case of study in a bioclimatic building. Journal of Process Control, 24, 703-713.

Cirre, C. R. M. (2007). Control jerárquico de la producción de energía mediante plantas de colectores solares distribuidos. Ph.D. thesis Universidad de Almería.

De Andrade, G., Álvarez, J., Pagano, D., \& Berenguel, M. (2015). Nonlinear controllers for solar thermal plants: A comparative study. Control Engineering Practice, 43, 12-20.

De Keyser, R., \& Ionescu, C. M. (2003). The disturbance model in model based predictive control. In Proceedings of 2003 IEEE Conference on Control Applications, 2003. CCA 2003. (pp. 446-451). IEEE volume 1.

Dinter, F., \& Gonzalez, D. M. (2014). Operability, reliability and economic benefits of CSP with thermal energy storage: first year of operation of ANDASOL 3. Energy Procedia, 49, 2472-2481. 
Duffie, J. A., \& Beckman, W. A. (2013). Solar engineering of thermal processes. John Wiley \& Sons.

Gallego, A. J., Merello, G. M., Berenguel, M., \& Camacho, E. F. (2019). Gainscheduling model predictive control of a Fresnel collector field. Control Engineering Practice, 82, 1-13.

Gibb, D., Johnson, M., Romaní, J., Gasia, J., Cabeza, L. F., \& Seitz, A. (2018). Process integration of thermal energy storage systems-evaluation methodology and case studies. Applied Energy, 230, 750-760.

Gil, J. D., Roca, L., Berenguel, M., \& Guzmán, J. L. (2018a). A multivariable controller for the start-up procedure of a solar membrane distillation facility. IFAC-PapersOnLine, 51, 376-381.

Gil, J. D., Roca, L., Ruiz-Aguirre, A., Zaragoza, G., \& Berenguel, M. (2018b). Optimal operation of a solar membrane distillation pilot plant via nonlinear model predictive control. Computers \&3 Chemical Engineering, 109, 151-165.

Gil, J. D., Roca, L., Zaragoza, G., \& Berenguel, M. (2018c). A feedback control system with reference governor for a solar membrane distillation pilot facility. Renewable Energy, 120, 536-549.

Guédez, R., Spelling, J., \& Laumert, B. (2015). Reducing the number of turbine starts in concentrating solar power plants through the integration of thermal energy storage. Journal of Solar Energy Engineering, 137, 011003.

Kolb, G. J. (2011). Evaluation of annual performance of 2-tank and thermocline thermal storage systems for trough plants. Journal of Solar Energy Engineering, 133, 031023.

Kumar, A., Prakash, O., \& Dube, A. (2018). A review on technology and promotional initiatives for concentrated solar power in world. International Journal of Ambient Energy, 39, 297-316. 
Kuravi, S., Trahan, J., Goswami, D. Y., Rahman, M. M., \& Stefanakos, E. K. (2013). Thermal energy storage technologies and systems for concentrating solar power plants. Progress in Energy and Combustion Science, 39, 285-319.

Li, J., Gao, G., Kutlu, C., Liu, K., Pei, G., Su, Y., Ji, J., \& Riffat, S. (2019). A novel approach to thermal storage of direct steam generation solar power systems through two-step heat discharge. Applied Energy, 236, 81-100.

Löfberg, J. (2004). Yalmip : A toolbox for modeling and optimization in matlab. In In Proceedings of the CACSD Conference. Taipei, Taiwan.

Lopez-Alvarez, M., Flores-Tlacuahuac, A., Ricardez-Sandoval, L., \& RiveraSolorio, C. (2018). Optimal start-up policies for a solar thermal power plant. Industrial \& Engineering Chemistry Research, 57, 1026-1038.

MATLAB (2018). MATLAB Optimization Toolbox Release 2018a. The MathWorks, Natick, MA, USA.

Normey-Rico, J. E., Bordons, C., Berenguel, M., \& Camacho, E. F. (1998). A robust adaptive dead-time compensator with application to a solar collector field. IFAC Proceedings Volumes, 31, 93-98.

Normey-Rico, J. E., \& Camacho, E. F. (2007). Control of dead-time processes. Springer Science \& Business Media.

Pawlowski, A., Guzmán, J. L., Rodríguez, F., Berenguel, M., \& Normey-Rico, J. E. (2011). Predictive control with disturbance forecasting for greenhouse diurnal temperature control. IFAC Proceedings Volumes, 44, 1779-1784.

Pelay, U., Luo, L., Fan, Y., Stitou, D., \& Rood, M. (2017). Thermal energy storage systems for concentrated solar power plants. Renewable and Sustainable Energy Reviews, 79, 82-100.

Plucenio, A., Pagano, D., Bruciapaglia, A., \& Normey-Rico, J. (2007). A practical approach to predictive control for nonlinear processes. IFAC Proceedings Volumes, 40, 210-215. 
Relloso, S., \& Delgado, E. (2009). Experience with molten salt thermal storage in a commercial parabolic trough plant. andasol-1 commissioning and operation. In Proceedings of 15th International SolarPACES Symposium, Sept (pp. $14-18)$.

Roca, L., Berenguel, M., Yebra, L. J., \& Alarcón-Padilla, D. C. (2008). Solar field control for desalination plants. Solar Energy, 82, 772-786.

Rovira, A., Montes, M. J., Valdes, M., \& Martínez-Val, J. M. (2011). Energy management in solar thermal power plants with double thermal storage system and subdivided solar field. Applied Energy, 88, 4055-4066.

Rubio, F. R., Navas, S. J., Ollero, P., Lemos, J. M., \& Ortega, M. G. (2018). Control óptimo aplicado a campos de colectores solares distribuidos. Revista Iberoamericana de Automática e Informática industrial, 15, 327-338.

Sebastián, A., Abbas, R., Valdés, M., \& Casanova, J. (2018). Innovative thermal storage strategies for fresnel-based concentrating solar plants with east-west orientation. Applied Energy, 230, 983-995.

Usaola, J. (2012). Operation of concentrating solar power plants with storage in spot electricity markets. IET renewable power generation, 6, 59-66.

Zaragoza, G., Ruiz-Aguirre, A., \& Guillén-Burrieza, E. (2014). Efficiency in the use of solar thermal energy of small membrane desalination systems for decentralized water production. Applied Energy, 130, 491-499. 